\title{
Is myometrial inflammation a cause or a consequence of term human labour?
}

\author{
Natasha Singh ${ }^{1,2}$, Bronwen Herbert ${ }^{2}$, Gavin R Sooranna ${ }^{2}$, Nicolas M Orsi ${ }^{3}$, \\ Lydia Edey², Tathagata Dasgupta3, Suren R Sooranna1,2, Steven M Yellon ${ }^{4}$ and \\ Mark R Johnson ${ }^{1,2}$ \\ ${ }^{1}$ Chelsea and Westminster Hospital, London, UK \\ Institute of Reproductive and Developmental Biology, Imperial College London, London, UK \\ 3Leeds Institute of Cancer \& Pathology, Wellcome Trust Brenner Building, St James's University Hospital, Leeds, UK \\ ${ }^{4}$ Longo Center for Perinatal Biology, Loma Linda University School of Medicine, Loma Linda, California, USA
}

Correspondence should be addressed to M R Johnson Email

mark.johnson@imperial.ac.uk

\begin{abstract}
Myometrial inflammation is thought to have a pivotal role in the onset of term and some forms of preterm labour. This is based on the comparison of samples taken from women undergoing term elective CS prior to the onset of labour with those taken from women in established labour. Consequently, it is not clear whether myometrial inflammation is a cause or a consequence of labour. Our objective is to test the hypothesis that myometrial inflammation is a consequence of the onset of labour. To test this hypothesis, we have obtained myometrial samples from women at various stages of pregnancy and spontaneous labour and studied the activation of the AP-1 (c-Jun) and NFKB (p65) systems, cytokine mRNA expression and protein levels and inflammatory cell infiltration and activation. We found that the activation of p65 declined from preterm to term not in labour samples and thereafter increased in early and established labour. Cytokine mRNA expression and protein levels increased in established labour only. Using flow cytometry of myometrial tissue, we found that the number of neutrophils did increase with the onset of labour, but on tissue section, these were seen to be intravascular and not infiltrating into the myometrium. These data suggest that myometrial inflammation is a consequence rather than a cause of term labour.
\end{abstract}

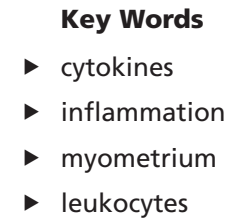

Journal of Endocrinology (2017) 235, 69-83

\section{Introduction}

The factors controlling the onset of human labour at term are unknown. Our failure to understand one of the most important of physiological processes means that our attempts to stop labour, when it occurs too soon, or to induce labour, when pregnancy is prolonged, are often unsuccessful and associated with significant morbidity and mortality. Certainly, prostaglandins and oxytocin are key players in the final common pathway, promoting myometrial contractility, meaning that their agonists and, in the case of oxytocin, antagonists, are commonly used to promote and inhibit contractions, respectively. However, the use of tocolytics, including the oxytocin receptor antagonist, Atosiban, does not improve neonatal outcomes (Haram et al. 2015) and neither prostaglandins nor oxytocin are universally successful when used for the induction of labour, where both have the propensity to cause uterine hyperstimulation and fetal hypoxia (Wing \& Sheibani 2015). These observations support the assertion made by the WHO that no progress will be made in the

Published by Bioscientifica Ltd. 
management of preterm labour until we understand the processes involved in human labour.

Myometrial inflammation is held to play a key role in the onset of labour, repressing progesterone action (Pieber et al. 2001, Condon et al. 2006), driving prolabour gene expression, including prostaglandin biosynthetic enzymes (Lindstrom \& Bennett 2005) and the oxytocin receptor (Terzidou et al. 2006). Increased myometrial prostaglandin and oxytocin activity promote myometrial contractility (Smith 2007) and, in the case of prostaglandins, contribute to the functional withdrawal of progesterone (Mesiano et al. 2002, Madsen et al. 2004). Myometrial inflammation was originally described by Azziz and coworkers, in a study investigating the occurrence of endomyometritis post Caesarean section (CS) (Azziz et al. 1988). This study showed that myometritis and chorioamnionitis occurred in 10\% of asymptomatic intrapartum CSs and suggested that infection was involved in the onset of term labour in some cases (Azziz et al. 1988). Later publications from Norman and coworkers emphasized the association between labour and inflammation, demonstrating an intense inflammatory myometrial infiltration of monocytes, neutrophils and macrophages (Thomson et al. 1999, Young et al. 2002, Osman et al. 2003). All myometrial gene array studies have identified inflammation as a key component of labouring myometrium (Bisits et al. 2005, Esplin et al. 2005, Breuiller-Fouche \& Germain 2006, Bollapragada et al. 2009, Mittal et al. 2010, Weiner et al. 2010). In more recent publications, Norman and coworkers have shown that inflammatory cytokines, bacterial lipopolysaccharide (LPS) and monocytes themselves can increase myometrial cell contractions, the first through increased prostaglandin synthesis and the second through a direct effect on ROCK activity (Hutchinson et al. 2014, Rajagopal et al. 2015). Interestingly, the pro-contractile effect of monocyte culture medium could be reversed by progesterone (Rajagopal et al. 2015). This is consistent with the existence of a mutually antagonist relationship between progesterone and inflammation, which is the basis of several theories for the onset of labour (Pieber et al. 2001, Condon et al. 2006, Hardy et al. 2006).

Collectively, these data show that labour is associated with inflammation and that inflammation can drive the onset of labour, but why would the myometrium become inflamed? Two mechanisms have been proposed, the first involves the secretion by the mature fetal lung of surfactant protein A (SP-A), which activates the pro-inflammatory transcription factor $\mathrm{NF \kappa B}$ (Condon et al. 2004); interestingly, the SP-A-knockout mouse has delayed parturition (Montalbano et al. 2013). The second theory involves myometrial stretch, whereby the growing pregnancy increases myometrial wall strain, activating the pro-inflammatory transcription factors $\mathrm{NF \kappa B}$ and AP-1, which drive the expression of pro-inflammatory cytokines (Hua et al. 2012). This last theory is supported by the observation of increased rates of preterm labour in conditions such as multiple pregnancy, polyhydramnios and uterine malformations (Stock \& Norman 2010) and the observation of an inflammatory pulse in response to inflation of intra-amniotic balloons in a non-human primate model of stretch-induced preterm labour (Adams Waldorf et al. 2015). However, despite the fact that there are plausible reasons for myometrial inflammation to occur, the key question remains; does myometrial inflammation actually occur prior to the onset of labour or is it simply a consequence of labour?

In the current study, we obtained myometrial samples from women at various stages of pregnancy and spontaneous labour and studied the activation of the AP-1 (c-Jun) and NFkB (p65) systems, cytokine profile and inflammatory cell infiltration in order to define when myometrial inflammation occurs in relation to the onset of labour. We reason that if myometrial inflammation is responsible for the onset of labour, then it should be present in the latent phase of labour, which we refer to as early labour; if, on the other hand, myometrial inflammation is a consequence of labour, then, it will only be apparent in samples obtained after labour is established.

\section{Materials and methods}

\section{Tissue collection}

All procedures involving human tissues were conducted in compliance with the London-Chelsea Ethics Committee. Informed consent was obtained from all women prior to any tissue collection. The demographic details are shown in Table 1. Labour was defined as the presence of regular uterine contractions every $3-4 \mathrm{~min}$. To study the inflammatory changes during pregnancy, at the onset of labour and after labour occurred, it was important to further define labour into early (otherwise called latent) and established labour. Early labour, or the latent phase of labour, is the period between no labour and established labour; it is defined clinically as uterine contractions with a cervical dilatation of $3 \mathrm{~cm}$ or less. Established labour is defined clinically as uterine contractions with a cervical dilatation of $3 \mathrm{~cm}$ or more. In all the labouring women, the onset of labour was spontaneous and the progress

Published by Bioscientifica Ltd. 
Table 1 Clinical demographics of the myometrial samples.

\begin{tabular}{|c|c|c|c|c|}
\hline & $\begin{array}{l}\text { Preterm no labour } \\
\qquad(n=17)\end{array}$ & TNL $(n=19)$ & $\begin{array}{l}\text { Term early labour } \\
\qquad(n=21)\end{array}$ & $\begin{array}{l}\text { Term established labour } \\
\qquad(n=14)\end{array}$ \\
\hline Maternal age & $32 \pm 6$ & $34 \pm 6$ & $35 \pm 4$ & $36 \pm 3$ \\
\hline \multicolumn{5}{|l|}{ Parity } \\
\hline 0 & 12 & 3 & 12 & 4 \\
\hline 1 & 3 & 12 & 8 & 8 \\
\hline 2 & 2 & 3 & 1 & 1 \\
\hline 3 & & 0 & 0 & 1 \\
\hline 4 & & 1 & & \\
\hline BMI & $26.5 \pm 4.8$ & $25.5 \pm 4.8$ & $22.7 \pm 2.8$ & $22.6 \pm 3.2$ \\
\hline Gestational age (mean \pm s.D.) & $33.8 \pm 1.7$ & $39.3 \pm 0.8$ & $38.4 \pm 1.3$ & $39.5 \pm 1.0$ \\
\hline Length of rupture of membranes ( $h$ ) & N/A & N/A & $8.2 \pm 8.8$ & $9.3 \pm 9.5$ \\
\hline \multicolumn{5}{|l|}{ Indication for CS } \\
\hline PET & 8 & & & \\
\hline PET with IUGR & 4 & & & \\
\hline Abnormal CTG & 2 & & 4 & 4 \\
\hline Previous ruptured uterus & 1 & & & \\
\hline IUGR & 2 & & & \\
\hline Breech or transverse lie & 0 & 3 & 7 & 7 \\
\hline Previous CS & 0 & 13 & 6 & 2 \\
\hline Maternal request & & 3 & 4 & 1 \\
\hline $\begin{array}{l}\text { No of women with ruptured } \\
\text { membrane }\end{array}$ & 0 & 0 & 15 & 9 \\
\hline
\end{tabular}

of labour was normal. Women in whom oxytocin was used or who had prolonged rupture of membranes or chorioamnionitis were excluded.

Samples were obtained from 4 groups of women at preterm no labour (PTNL), term no labour (TNL), term early labour (TeL) and term established labour (TestL). The indications for the CS were for previous CS, breech presentation or fetal distress. From each woman, myometrial biopsies were taken from the upper aspect of the lower segment uterine incision. All the samples were collected and frozen at $-80^{\circ} \mathrm{C}$ immediately. We tried to use the same samples throughout the study and all the samples used for rt-PCR and multiplex assay were all matched. However, due to the number of experiments and limited amount of tissue available, for the active motif assays (c-Jun and p65 activation), 4 PTNL, 5 TNL and 4 TeL samples were not available.

\section{Cytokine mRNA expression in myometrial samples}

The mRNA levels of $I L-1 \beta, T N F \alpha, I L-6, I L-4, I L-10$, CCL2, CXCL8, CXCL1 and CXCL2 was determined in myometrial samples obtained from women (mean gestational age \pm S.D. and $n$ in each case) undergoing CS at PTNL $(33.8 \pm 1.7$ weeks, $n=17)$, TNL $(39.3 \pm 0.8$ weeks, $n=18$ ), TeL (cervical dilatation $3 \mathrm{~cm}, 38.4 \pm 1.3, n=14$ ) and TestL (cervical dilatation $>3 \mathrm{~cm}, 39.6 \pm 1.1$ weeks, $n=14$ ). The samples were homogenised using the Precellys 24 Dual system and CKMix tubes (Bertin Instruments, Paris, France) in RNA Stat (AMS Biotechnology, Milton, Oxfordshire, UK) according to the manufacturer's instructions. After chloroform addition and centrifugation, RNA extraction from the supernatant was completed using an RNeasy mini kit (Qiagen), as per the manufacturer's instructions. RNA quality and quantity was assessed using a NanoDrop (Thermo Scientific). After RNA quantification, 1.0 $\mu \mathrm{g}$ was reverse transcribed with oligo dT random primers using the MuLV reverse transcriptase system (Applied Biosystems), according to the manufacturer's protocols.

Primer sets for genes listed on Supplementary Table 1 (see section on supplementary data given at the end of this article) were designed and obtained from Invitrogen. Assays were validated for all primer sets by confirming that single amplicons of appropriate size and sequence were generated according to predictions. Quantitative PCR was performed in the presence of SYBR Green (Applied Biosystems), and amplicon yield was monitored during cycling in a RotorGene Sequence Detector (Qiagen) that continually measures fluorescence caused by the binding of the dye to double-stranded DNA. Pre-PCR cycle was $10 \mathrm{~min}$ at $95^{\circ} \mathrm{C}$ followed by up to 45 cycles of $95^{\circ} \mathrm{C}$ for $20 \mathrm{~s}$, $58-60^{\circ} \mathrm{C}$ for $20 \mathrm{~s}$ and $72^{\circ} \mathrm{C}$ for $20 \mathrm{~s}$ followed by an extension at $72^{\circ} \mathrm{C}$ for $15 \mathrm{~s}$. The final procedure involves a melt over the temperature range of $72-99^{\circ} \mathrm{C}$ rising by $1^{\circ}$ steps with a wait for $15 \mathrm{~s}$ on the first step followed by a wait of $5 \mathrm{~s}$ for each subsequent step. The cycle in which fluorescence reached a pre-set threshold (cycle threshold) was used for quantitative analyses. The cycle threshold in each

Published by Bioscientifica Ltd. 
assay was set at a level where the exponential increase in amplicon abundance was approximately parallel between all samples. GeNORM (Vandesompele et al. 2002) was used to identify and validate the most stable housekeeping genes among a group of candidate reference genes. We identified 2 housekeeping genes, GAPDH and CYC as the best set of reference genes for comparing myometrial samples. Average gene Ct values were normalized against the two housekeeping genes.

\section{Bio-Plex Pro cytokine multiplex assays}

Protein lysates were prepared from the frozen myometrial tissues, PTNL ( $33.8 \pm 1.7$ weeks, $n=17)$, TNL (39.3 \pm 0.8 weeks, $n=19)$, TeL $(38.4 \pm 1.3$ weeks, $n=21)$ and TestL $(39.5 \pm 1.0, n=14)$ using the Bio-Plex Pro cell signalling reagent kit (Bio-Rad Laboratories) and the Precellys24 Dual bead homogeniser system, according to the manufacturer's instructions. Lysate concentrations were quantified by DCTM Protein Assay (Bio-Rad). $500 \mu \mathrm{g}$ of protein lysate was added per well to a Bio-Plex 40-plex (analytes listed in Supplementary Table 2) and due to buffer incompatibility, onto an additional separate Bio-Plex CCL5 single-plex assay. Samples were run in singlicate due to the number of samples available and to allow all samples to be run on the same plate, thereby eliminating inter-plate variation in our analyses. Appropriate standards and controls were provided with the assays and both were completed in accordance with the manufacturer's instructions.

\section{Myometrial transcription factor activation}

We assessed the activity of the NFKB and MAPK/AP-1 pathways in myometrial tissue samples using a variety of techniques. Initially, we used western analysis, but this allowed for the comparison of relatively small numbers and is semi-quantitative (data not shown). We next tried a multiplex analysis (data not shown) and found the data were inconsistent with the western analysis and later methods (data not shown). Finally, we used a single factor ELISA and a DNA-oligomer-based active motif assay and found that these last 2 give consistent results and hence have presented the data from the active motif assays for c-Jun and p65.

\section{Active motif assay}

Relative levels of phospho-p65 and phospho-c-Jun were measured using TransAMTM NFkB and TransAMTM
AP-1 transcription factor DNA-protein-binding assays (Active Motif, Carlsbad, CA, USA) from women (mean gestational age \pm s.D. in each case), at preterm no labour (PTNL; $34.2 \pm 1.2$ weeks, $n=13$ ), term no labour (TNL; $39.3 \pm 0.8$ weeks, $n=14)$, TeL $(38.3 \pm 1.2$ weeks, $n=17)$ and TestL $(39.5 \pm 1.0, n=14)$. Whole cell lysates were prepared using a Precellys 24 bead homogenizer (Stretton Scientific Ltd, Stretton, Derbyshire, UK), with the Active Motif Nuclear Extraction Kit, in accordance with the manufacturer's instructions for preparations from frozen tissues. Protein concentrations were quantified using a DC Protein Assay (Bio-Rad). $100 \mu \mathrm{g}$ and $200 \mu \mathrm{g}$ of protein lysate were added per sample well for the TransAMTM AP-1 and TransAMTM NFkB respectively and diluted in the appropriate individual transcription factor assay lysis buffer. Assays were completed according to the manufacturer's instructions.

\section{Flow cytometry}

Myometrial tissue was weighed, cut finely and incubated on a rotator at $37^{\circ}$ for $40-50 \mathrm{~min}$ with liberase $(1 \mathrm{~mL} / 100 \mu \mathrm{g}$ of tissue; DNAse $200 \mu \mathrm{g} / \mathrm{mL}$, Liberase $100 \mu \mathrm{g} / \mathrm{mL}$ in PBS). Then, it was vigorously shaken and poured through a $40 \mu \mathrm{m}$ cell strainer with FACS wash buffer (FWB) (PBS/1\% human serum (Sigma)/1 mM EDTA (Sigma)) to a total of $15 \mathrm{~mL}$. The mixture was then centrifuged at $700 \boldsymbol{g}$ for $5 \mathrm{~min}$ and the supernatant was poured off, the pellet was dried with tissue paper and resuspended in FWB and then incubated with antibodies at $4^{\circ} \mathrm{C}$ for $30 \mathrm{~min}$. The neutrophils were defined as: CD11b+, CD45+, CD115+, CD56- and CD11c+ and the monocytes/macrophages defined as: CD11b+, CD45+, CD115-, CD56-, CD14+. The following antibodies were used: anti-humanCD11c (FITCCD11, cat no. 301603/4, BioLegend, San Diego, CA, USA), anti-human-CD115 (PECD115, cat no. 347303/4, BioLegend), anti-cd11b (PE-CF594CD11b CAT NO. 562317, BD Biosciences), anti-human-HLA-DR (PerCpCD66b cat no. 307609/10, BioLegend), antihuman-CD56 (PeCy7CD56 cat no. 318318, BioLegend), anti-human-HLA-DR (APC/Ax647HLADR/BLANK cat no. 307609/10, BioLegend) and anti-human-CD45 (Ax780CD45 304014, BioLegend).

\section{Immunohistochemistry}

A subset of the myometrial biopsies were used for histological analyses from the 3 groups of women TNL $(39.3 \pm 0.8$ weeks, $n=8)$, TeL $(39.6 \pm 1.1$ weeks, $n=7)$

Published by Bioscientifica Ltd 
and TestL $(38.5 \pm 1.3, n=8)$. Biopsies were immersion fixed in $4 \%$ paraformaldehyde, embedded in paraffin, sectioned and stained by immunohistochemistry with antigen retrieval for CD68 macrophages as previously described (Dubicke et al. 2016). To assess the density of macrophages and cell nuclei, brown CD68-stained cells associated with methyl green-stained cell nuclei, as well as the total number of cell nuclei/area in the myometrium were counted in 6-8 representative photomicrograph in 2 sections/biopsy. Analyses of each photomicrograph excluded areas with folds, tears or blood vessels. Images were analysed using the cell counter plugin as part of ImageJ. These same sections were also analysed using Stereologer software, an unbiased cell counting programme that takes a statistical approach to randomly sample volumes and spatial distributions within regions of interest (Gundersen \& Jensen 1987, Burke et al. 2009).

\section{Bayesian network construction}

The reader is referred to previous publications for a detailed account of the background and methodology of Bayesian network-based modelling of cytokine interactions (Field et al. 2015). Briefly, Bayesian networks are probabilistic graphical depictions of interacting variables in which the parameters investigated are nodes whose status is governed by that of its immediate parents, whilst their interactions are represented by directed edges underpinned by conditional probability tables quantifying the probability of the state of the daughter node (in this instance, relative concentration) given the state of its immediate upstream parent(s). Prior (seed) networks containing proteins from analytical target sets were learned from a combination of relationships established from the biomedical literature and proteinprotein interaction databases. Agilent Literature Search (www.agilent.com/labs/research/litsearch.html) and MetaCore Inc. (https://lsresearch.thomsonreuters.com/ pages/solutions/1/metacore) were used to generate the prior networks along with thorough hand curation. The resultant seed networks were combined with results from the text mining web application Predictionet (www.bioconductor.org/packages/devel/bioc/html/ predictionet.html). Conflicting network edges, which caused feedback cycles, were eliminated as Bayesian networks inherently preclude the existence of structural cycles. Typically, the network structure close to the prior network has the higher probability and the parametric formula for this scoring metric prior structure-related factor has been given elsewhere (Field et al. 2015). In order to establish a high-confidence network, a machine-learning algorithm implemented in the WEKA-based MeV package (www.cs.waikato.ac.nz/ml/weka/) was employed to refine the seed network in conjunction with the experimental data. Prior to conducting the Bayesian analysis, raw data were normalised using z-scores and discretised into categorical data using z-scores in Matlab before being assigned to three mutually exclusive equal size relative concentration bins each represented by a colour code (low, red; intermediate, white; high, green) determined by its own allied underlying histogram. These data were used to learn the Bayesian network. Only nodes a maximum of three parents were selected, as per convention in the field. Very high stringency (confidence $=0.9$; i.e. features occurring in $\geq 90 \%$ of iterations) non-parametric bootstrapping was applied (100 operations) to address any potential overfitting and increase the robustness of the Bayesian analysis. This was achieved by creating multiple data sets by resampling with replacement in order to obtain a measure of the confidence in the various network interactions. A combination of metrics and search algorithms was used to optimise result sensitivity (the Tabu Search algorithm was used to optimize the Bayes (BDe) score as the selected scoring metric). The directed acyclic graph was then portrayed using Cytoscape (www.cytoscape.org).

\section{Statistical analysis}

All data were initially tested for normality using a Kolmogorov-Smirnoff test. Normally distributed data were analysed using a Student's $t$-test for two groups and an ANOVA followed by a Dunnett's or Bonferroni's post hoc test for three groups or more. Data that were not normally distributed were analysed using a Wilcoxon matched pair test for paired data and when comparing three groups or more a Friedman's test, with a Dunn's multiple comparisons post hoc test. A $P$ value of $<0.05$ was considered statistically significant.

\section{Results}

\section{Clinical characteristics of the myometrial samples}

Table 1 summarizes the clinical characteristics of the myometrial samples for the PTNL, TNL, TeL and TestL groups used for the PCR and multiplex Bio-Rad assay.

Published by Bioscientifica Ltd. 


\section{Myometrial transcription factor activation}

We assessed the activity of the NFKB and MAPK/AP-1 pathways in myometrial tissues. Intriguingly, the binding of p65 was greater in the PTNL samples compared to the TNL (Fig. 1A). However, with the onset of labour, p65 binding increased progressively, being greater in both the TeL and TestL samples than that in the TNL samples (Fig. 1B). In contrast, c-Jun binding did not change (Fig. 1B and D).

\section{Myometrial cytokine mRNA expression}

No differences were found in samples from PTNL and TNL women for the mRNA expression of a range of cytokines: pro-inflammatory (IL-1 $\beta, T N F \alpha, I L-6$; Fig. 2A, B and C), anti-inflammatory ( $I L-4$ and $I L-10$, Fig. 2D and E) and chemokines (CCL2, CXCL8, 1 and 2, Fig. 2F, G, H and I). In samples obtained from women at TNL, TeL and TestL, the mRNA expression of $I L-6$ ( $P<0.01$, Fig. 4C), CXCL8 $(P<0.001$, Fig. 4G) and CXCL1 $(P<0.01$, Fig. 4H) was greater in TestL samples compared to TNL samples. The increase in $I L-1 \beta$ mRNA expression did not reach significance $(P=0.059$, Fig. $4 \mathrm{~A})$.

\section{Myometrial cytokine protein levels}

Representative cytokines levels, matching the mRNA data above, are shown in Figs 3, 4 and 5 with the remainder shown in Supplementary Figs 1, 2 and 3. There were no differences between PTNL and TNL samples (Fig. 3). In the term myometrial samples, the levels of IL-1 $\beta(P<0.05$, Fig. 5A), IL-6 $(P<0.001$, Fig. 5C), IL-4 $(P<0.01$, Fig. 5D), IL-10 $(P<0.01$, Fig. 5E), CCL2 $(P<0.01$, Fig. 5F), CXCL8 $(P<0.01$, Fig. 5G), CXCL1 $(P<0.01$, Fig. 5H) and CXCL2 $(P<0.05$, Fig. 5I) increased in TestL compared to TNL samples. For the Supplementary Figs 1, 2 and 3, significant differences were seen between term established labour samples and TNL and/or TeL samples; there were no differences between TNL and TeL for any of the analytes (Supplementary Figs 1, 2 and 3).

\section{Myometrial inflammatory cell infiltration}

We used flow cytometry and immunohistochemistry to assess the changes in myometrial inflammatory cell numbers between TNL and TeL samples.

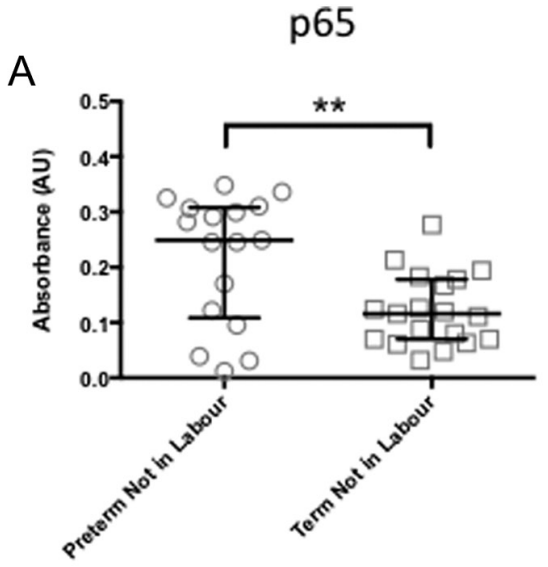

C

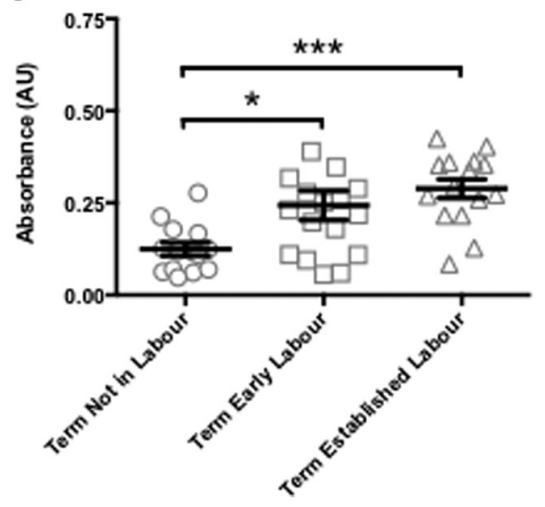

$\mathrm{B}$

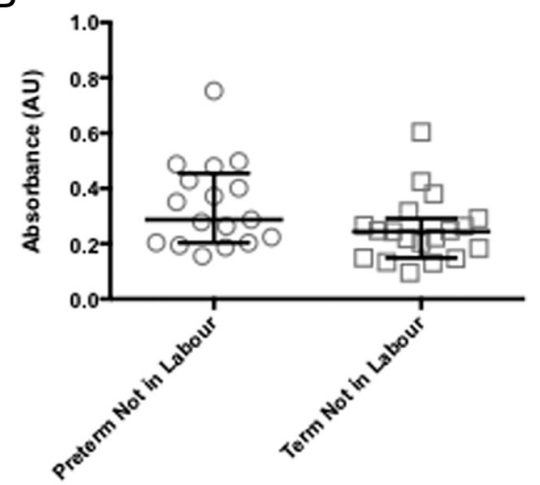

D

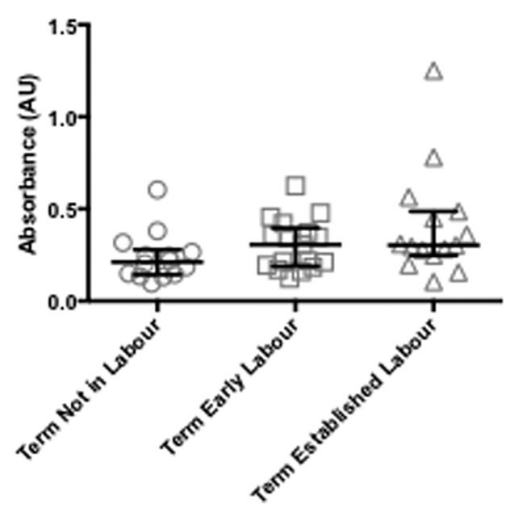

Figure 1

( $A, B, C$ and $D$ ) Lower segment human myometrial samples were obtained from four groups of women at the time of Caesarean section from women (mean gestational age \pm S.D. in each case), at preterm no labour ( $33.5 \pm 2.0$ weeks, $n=18)$, TNL $(39.3 \pm 0.8$ weeks, $n=18)$, early labour (cervical dilatation $<3 \mathrm{~cm}, 39.6 \pm 1.1$ weeks, $n=14$ ) and established labour (cervical dilatation $>3 \mathrm{~cm}$, $38.5 \pm 1.3, n=14$ ). The samples were homogenised and relative levels of phospho-p65, NFKB and phospho-c-Jun were measured using TransAMTM NFkB and TransAMTM AP-1 transcription factor DNA-protein-binding assays (Active Motif, Carlsbad, CA, USA). Normally distributed data were analysed using a Student's $t$-test for two groups and an ANOVA followed by a Dunnett's or Bonferroni's post hoc test for three groups or more. Data that were not normally distributed were analysed using a Mann-Whitney test for 2 groups and when comparing three groups or more a Friedman's test, with a Dunn's multiple comparisons post hoc test. The data are shown as median with interquartile ranges. The $P$ values are demonstrated by $* P<0.05, * * P<0.01$ and $* * * P<0.001$. 
A

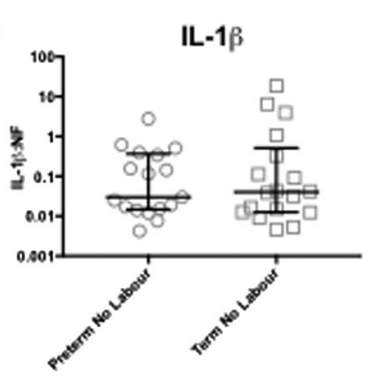

D

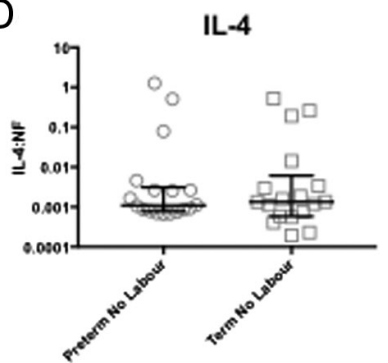

F

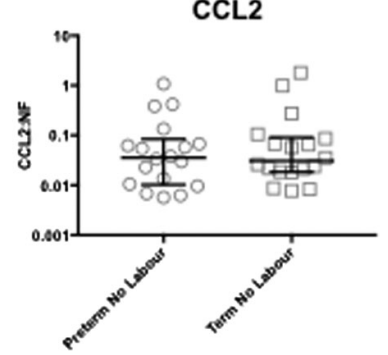

B

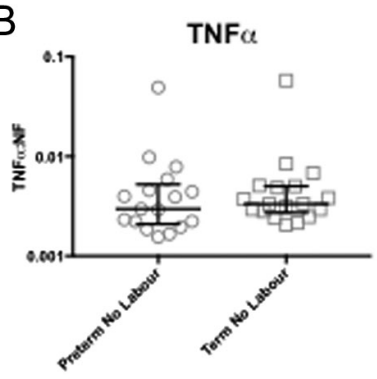

E

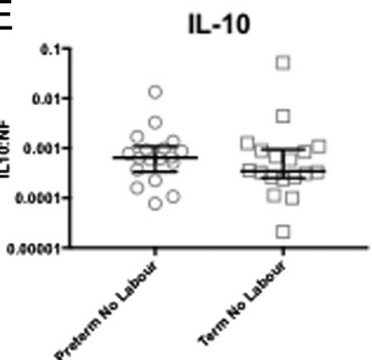

G

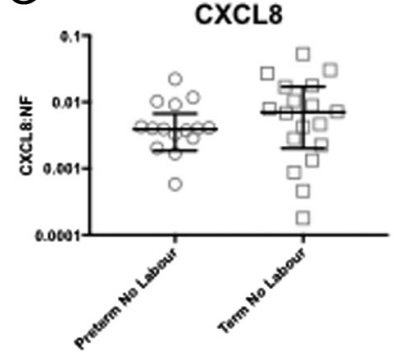

C

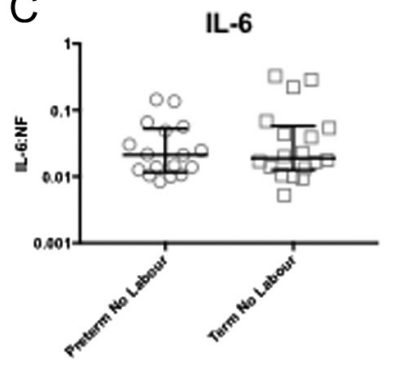

$\mathrm{H}$

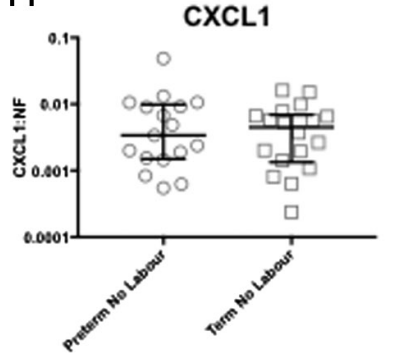

I

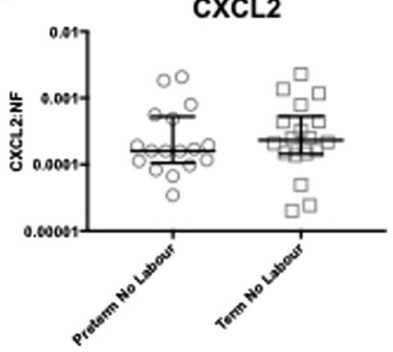

Figure 2

( $A, B, C, D, E, F, G, H$ and I) Lower segment human myometrial samples were obtained from two groups of women at the time of Caesarean section (mean gestational age \pm s.D. in each case), at preterm no labour $(33.5 \pm 2.0$ weeks, $n=18)$ and TNL $(39.3 \pm 0.8$ weeks, $n=18)$. The samples were homogenised and RNA was extracted and converted to CDNA. Copy numbers of IL-1 $\beta$, TNF $\alpha$, IL-6, IL-4, IL-10, CCL2, CXCL8, CXCL1 and CXCL2 mRNA were measured by quantitative rtPCR. The data were not normally distributed and were analysed using a Mann-Whitney test for 2 groups. The data are shown as median with interquartile range.

The flow cytometry data suggested that the numbers of neutrophils increased in the myometrium in TeL $(P<0.05$, Fig. 6A), but not in the blood (Fig. 6C). Monocyte and macrophage numbers were unaltered in both locations (Fig. 6B and D). Analysis of the tissue sections suggested that the neutrophils were predominately a marginated intravascular or perivascular population and that they had not entered the myometrium itself (Fig. 7A). CD68-stained macrophages were evident in myometrium among all groups of pregnant women at term (Fig. 7B). The density of cell nuclei and macrophages was not significantly different whether women were in or not in labour. Counting of cell nuclei/area and macrophages using non-biased stereology replicated results of manual procedures.

\section{Bayesian networks}

\section{Preterm no labour}

Preterm non-labouring networks featured all nodes at relatively low concentration (Supplementary Fig. 4). Most principal parents remained conserved relative to other networks, featuring CCL8, CCL20, CTACK (CCL27), eotaxin, eotaxin-2, GCP-2, GM-CSF, IL-1 $\beta$, I-TAC (CXCL11), MDC (CCL22), MIF, MIG, MIP-1 $\alpha$ (CCL3), RANTES and TNF- $\alpha$. CCL25 was confined to a side branch. Terminal nodes were broadly similarly conserved and included CCL1, CCL2, CCL15, CCL17, CCL19, CCL23, GRO- $\alpha$, IL-16 and SDF-1 $\alpha$ (CXCL12). The previous definition of a structural hub that we have used was a node with $>1$ input and output edges totalling $\geq 5$ 
A

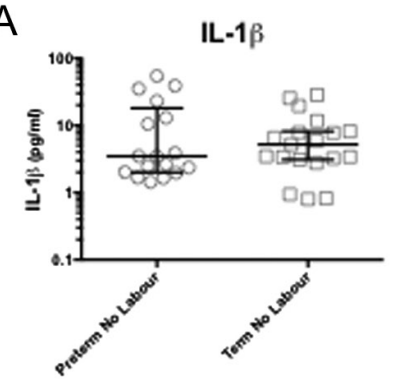

D

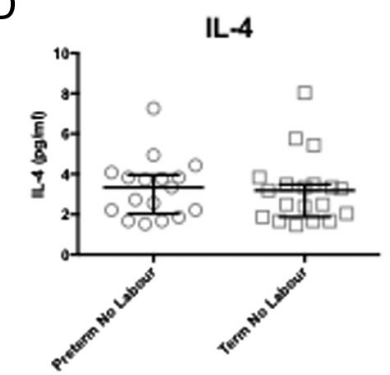

$\mathrm{F}$

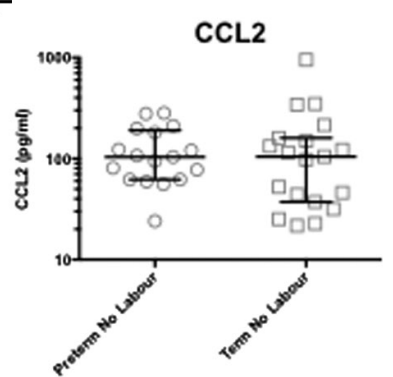

B

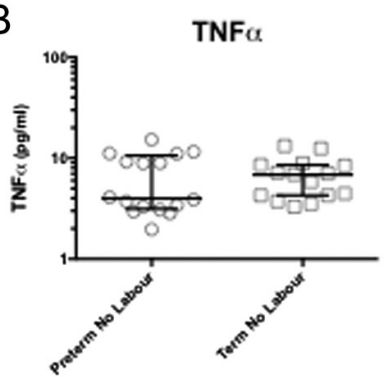

E

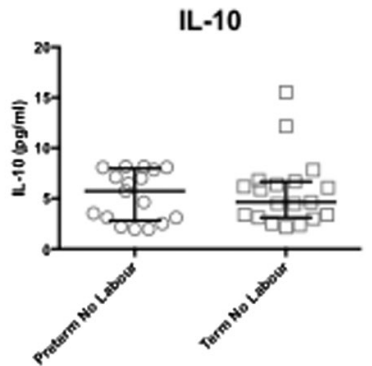

G

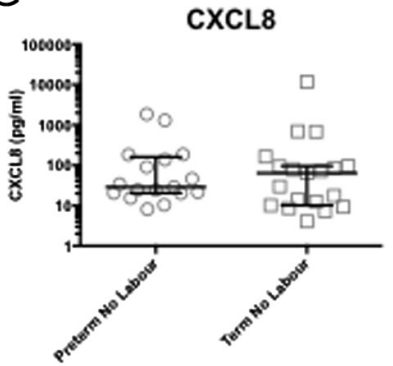

C

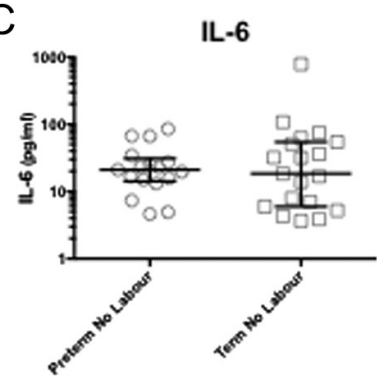

$\mathrm{H}$

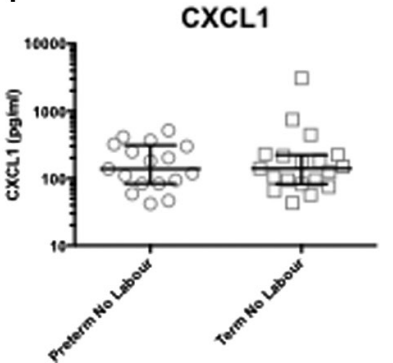

I

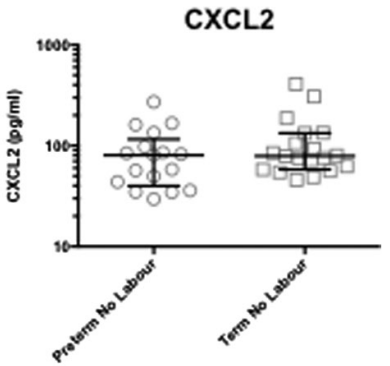

Figure 3

( $A, B, C, D, E, F, G, H$ and I) Lower segment human myometrial samples were obtained th the time of Caesarean section from the following women: preterm no labour $(33.5 \pm 2.2$ weeks, $n=18)$ and TNL $(39.3 \pm 0.8$ weeks, $n=19)$ and chemokine protein levels were measured (Bio-plex human cytokine 40-plex-array kit, Bio-Rad). The protein content of the samples was established by serial dilutions, before cytokine analysis in the multiplex assay using an 8-point calibration curve for each individual analyte produced from manufacturer-supplied set standards of known concentration and presented as concentrations $(\mathrm{pg} / \mathrm{mL})$. Normally distributed data were analysed using a Student's $t$-test for two groups and not normally distributed were analysed using a Mann-Whitney test for 2 groups. The data are shown as median with interquartile range.

(Field et al. 2015). None of the nodes herein met these criteria, although some hub-like integrative features were noted for GRO- $\beta$ (CXCL2) (4 inputs, 1 output), IFN- $\gamma$ (3 inputs, 2 outputs), IL-2 ( 2 inputs, 5 outputs), IL-6 (5 inputs, 2 outputs) and IL-8 (CXCL8, 5 inputs, 1 output). CXCL13 and CXCL16 were orphaned from the network.

\section{Term no labour}

TNL networks were characterized by a complex network (in terms of the number of parents and terminal nodes) wherein all mediators were present at relatively low concentrations (Supplementary Fig. 5). Multiple terminal nodes were identified, including SDF-1 $\alpha$ (CXCL12) (major), CCL1, CCL2, CCL15, CCL17, CCL19, CCL23, eotaxin-3, GRO- $\alpha$ (CXCL1) and IL-16 (minor). Several original parents were also seen, RANTES and TNF- $\alpha$ most prominently, but also CCL8, CCL20, CCL21, CCL25, CTACK (CCL27), eotaxin, eotaxin-2, GCP-2, GM-CSF, IL-1 $\beta$, I-TAC (CXCL11), MDC (CCL22), MIF, MIG and MIP-1 $\alpha$ (CCL3). None of the nodes herein met these criteria, although some hub-like features were noted for GRO- $\beta$ (CXCL2, 4 inputs, 1 output), IFN- $\gamma$ (3 inputs, 2 outputs), IL-2 (2 input edges, 3 output edges), IL-6 (5 inputs, 2 outputs) and IL-8 (CXCL8, 5 inputs, 1 output). CXCL13 and CXCL16 were both orphaned from the network. 
A

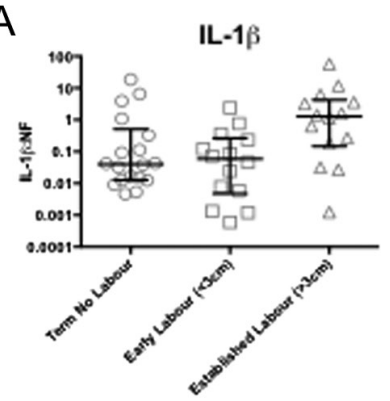

D

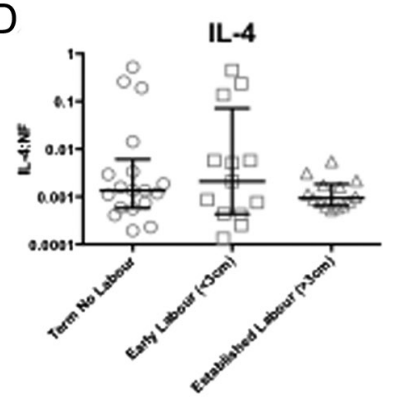

F

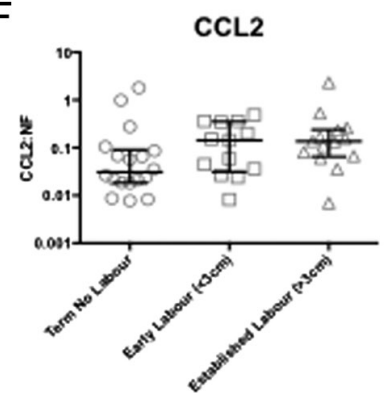

B

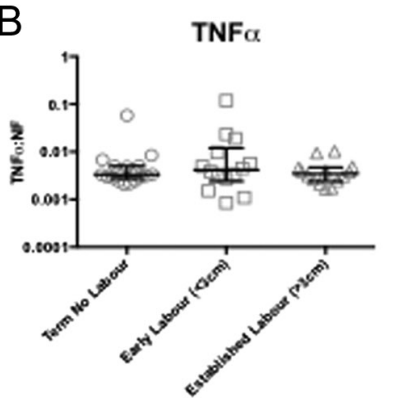

E

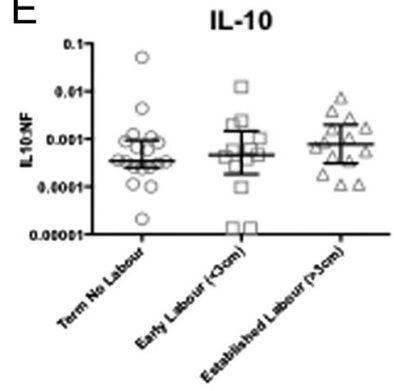

G

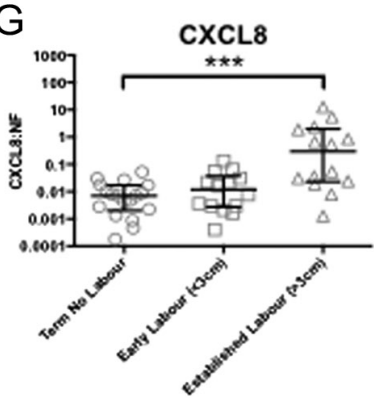

C

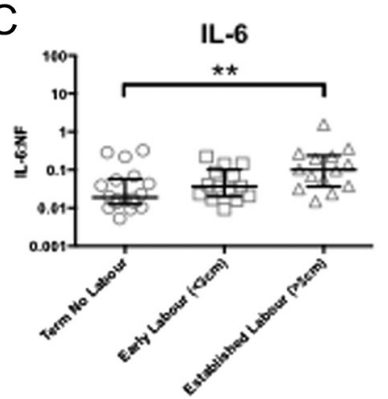

$\mathrm{H}$

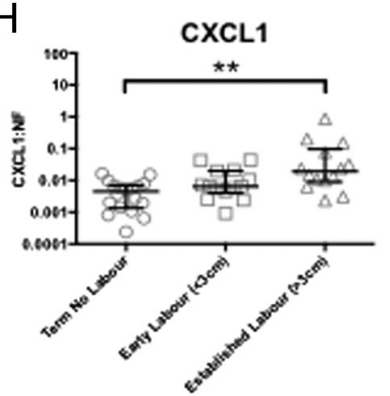

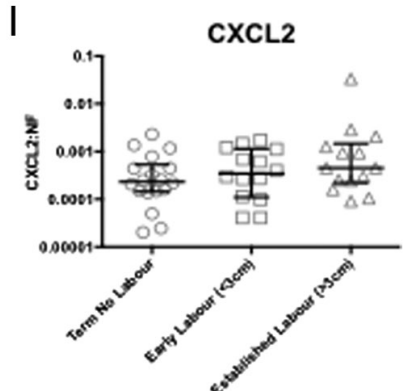

Figure 4

( $A, B, C, D, E, F, G, H$ and I) Lower segment human myometrial samples were obtained from three groups of women at the time of Caesarean section from women (mean gestational age \pm S.D. in each case), at TNL ( $39.3 \pm 0.8$ weeks, $n=18$ ), early labour (cervical dilatation $<3 \mathrm{~cm}, 39.6 \pm 1.1$ weeks, $n=14$ ) and established labour (cervical dilatation $>3 \mathrm{~cm}, 38.5 \pm 1.3, n=14$ ). The samples were homogenised and RNA was extracted and converted to cDNA. Copy numbers of IL-1 $\beta$, TNF $\alpha$, IL-6, IL-4, IL-10, CCL2, CXCL8, CXCL1 and CXCL2 mRNA for the TNL, early and term established labour samples were measured by quantitative rtPCR. The data were not normally distributed and were analysed using a Friedman's test, with a Dunn's multiple comparisons post hoc test. The data are shown as median with interquartile range. The $P$ values are demonstrated by $* * P<0.01$ and $* * * P<0.001$.

\section{Term early labour}

TeL networks featured I-TAC (CXCL11) as the only node at relatively high concentration, while all others remained at low concentration with the exception of CCL15, which was at intermediate concentration (Supplementary Fig. 6). Principal parents included CCL20, CCL21, CTACK (CCL27), eotaxin-2, GM-CSF, IL-1 $\beta$, I-TAC (CXCL11), MDC (CCL22), MIF, MIG, MIP-1 $\alpha$ (CCL3), RANTES and TNF- $\alpha$. Terminal nodes comprises CCL1, CCL2, CCL8, CCL15, CCL19, CCL23, CX3CL1, CXCL16, IL-16 and, with multiple input edges, SDF-1 $\alpha$ (CXCL12). Nodes with hub-like features included eotaxin (1 input, 4 outputs), GRO- $\beta$ (CXCL2, 4 inputs, 1 output), IFN- $\gamma$ (3 inputs, 3 outputs), IL-2 (2 inputs, 3 outputs), IL-6 (5 inputs,
2 outputs) and IL-8 (CXCL8, 4 inputs, 2 outputs). CXCL13 was the only node orphaned from the network.

\section{Term established labour}

Term established labour networks featured CTACK (CCL27) at relatively high concentration, unlike all its counterparts (Supplementary Fig. 7). Most principal parents were conserved; most prominent were CTACK (CCL27), RANTES and TNF- $\alpha$, but also CCL8, CCL20, eotaxin, eotaxin-2, GCP-2, GM-CSF, IL-1 $\beta$, MDC (CCL22), MIG, I-TAC (CXCL11), MIF and MIP-1 $\alpha$ (CCL3). CCL21 was confined to a side branch. Fewer terminal nodes were identified, principally SDF-1 $\alpha$ (CXCL12); all the 
A

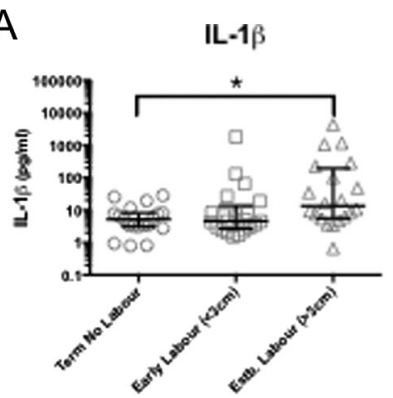

D

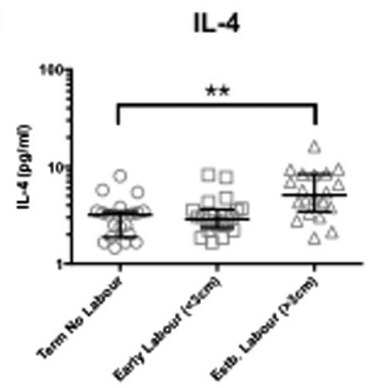

$\mathrm{F}$

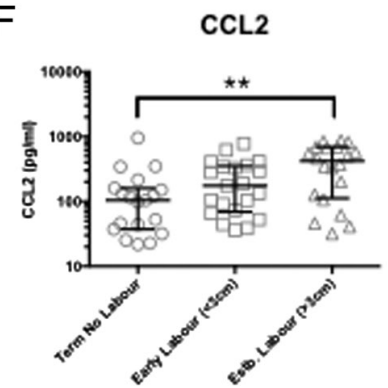

B

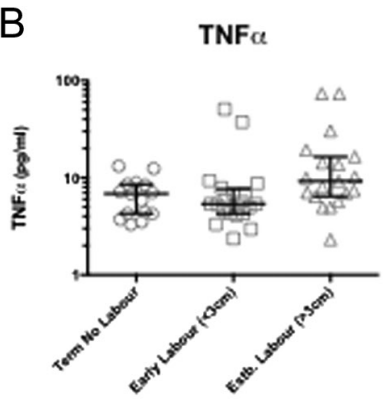

E

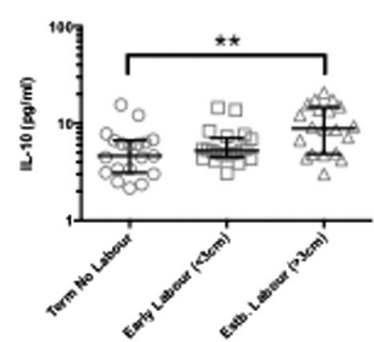

G

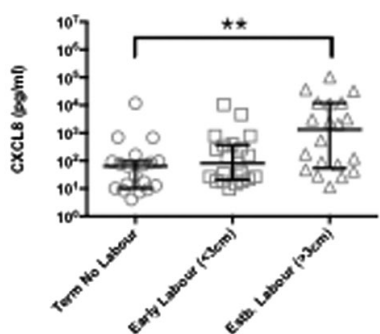

C

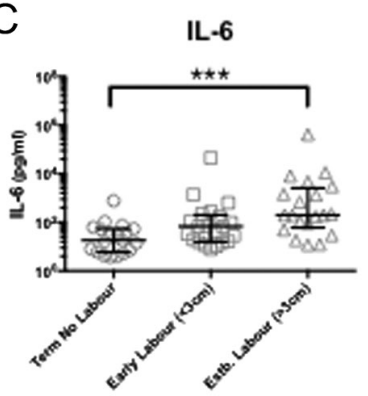

Figure 5

(A, B, C, D, E, F, G, H and I) Lower segment human myometrial samples were obtained at the time of Caesarean section and used to compare the cytokine protein levels in three groups of women: TNL ( $39.3 \pm 0.8$ weeks, $n=19)$, TeL $(38.4 \pm 1.3$ weeks, $n=21)$ and term established labour (39.5 \pm 1.0 , $n=14)$. After the protein content of the samples was established by serial dilutions, the cytokines were quantified using Bio-plex human cytokine 40-plex-array kit (Bio-Rad) using an 8-point calibration curve for each individual analyte produced from manufacturer-supplied set standards of known concentration and presented as concentrations $(\mathrm{pg} / \mathrm{mL})$. Normally distributed data were analysed using an ANOVA followed by a Dunnett's or Bonferroni's post hoc test and not normally distributed were analysed using a Friedman's test, with a Dunn's multiple comparisons post hoc test. The data are shown as median with interquartile range. The $P$ values are demonstrated by $* P<0.05$, $* * P<0.01$ and $* * * P<0.001$.

others were conserved relative to the non-labouring networks, viz., CCL2, CCL17, CCL19, CCL23, GRO- $\alpha$ (CXCL1) and IL-16. Nodes with hub-like features included GRO- $\beta$ (CXCL2, 4 inputs, 1 output) and some of those noted in early labouring networks being conserved, namely IL-2 (2 inputs, 3 outputs), IL-6 (5 inputs, 2 outputs) and IL-8 (CXCL8, 5 inputs, 1 output). CXCL13 and CXCL16 were again both orphaned from the network.

\section{Discussion}

Our data suggest that myometrial inflammation is a secondary event, present only with established labour and not preceding or occurring at the same time as the onset of labour. However, we did find evidence for the activation of the pro-inflammatory transcription factor NFkB in early labour, possibly driving the later increase in mRNA and protein levels of chemokines and proinflammatory cytokines. Also, we found that for many cytokines, protein levels increased in established labour without any increase in mRNA, suggesting a posttranscriptional regulation. Consistent with the later increase in chemokine levels, we found no evidence of inflammatory cell infiltration of the myometrium with the onset of labour.

Key to our conclusions is the distinction between early and established labour. In clinical practice, the first 
A
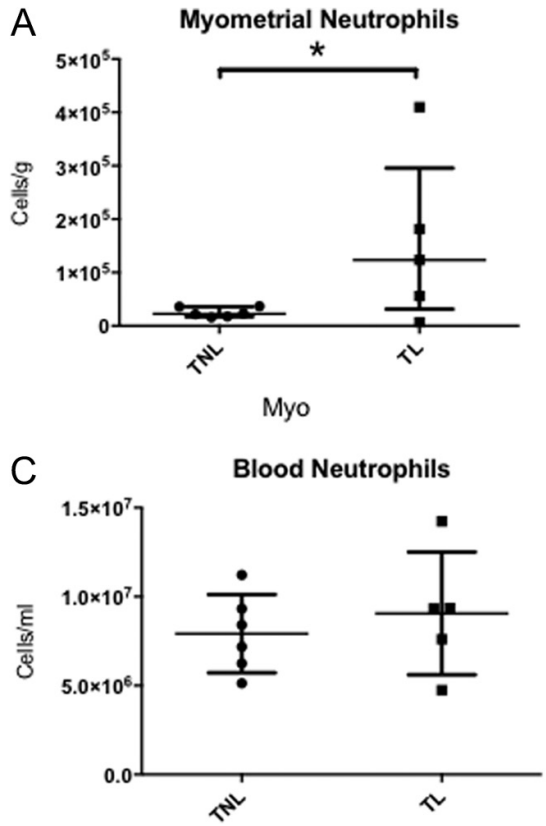
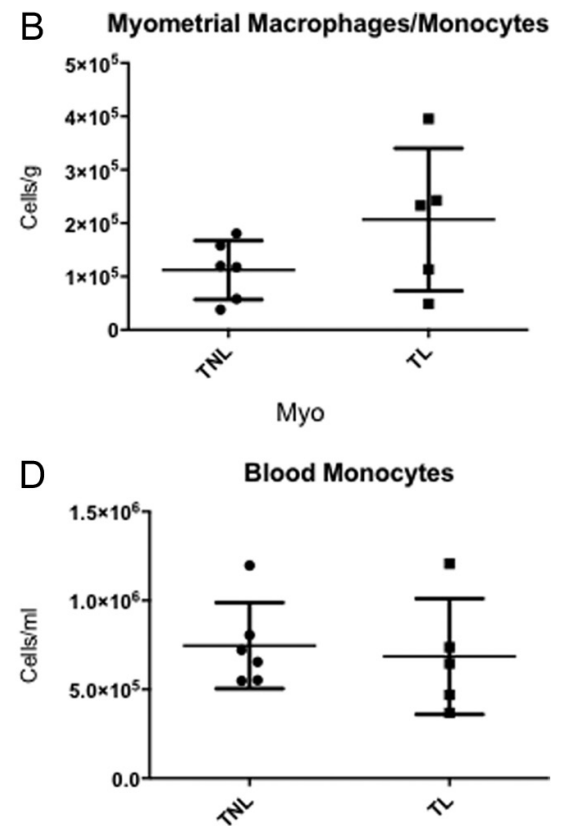

\section{Figure 6}

( $A, B, C$ and $D$ ) Lower segment human myometrial samples were obtained at the time of Caesarean section and used for flow cytometry: TNL $(38.7 \pm 0.7$ weeks, $n=6)$, TeL $(38.9 \pm 1.1$ weeks, $n=5)$. The tissues were homogenised and the neutrophils defined as: CD11b+, CD45+, CD115+, CD56-, CD11C+ and the monocytes/macrophages defined as: CD11b+, CD45+, CD115-, CD56-, CD14+. Normally distributed data were analysed using a Student's $t$-test for two groups and data that were not normally distributed were analysed using a Mann Whitney test for 2 groups. The data are shown as median with interquartile range. The $P$ values are demonstrated by $* P<0.05$. stage of labour consists of two phases: the latent phase (early labour) and the active phase. The latent phase has been described as 'a period of time when there are painful contractions, and there is some cervical change, including cervical dilatation up to $4 \mathrm{~cm}^{\prime}$ (NICE 2014). In this study, we have collected samples from women in the latent or early phase of labour who experienced contractions occurring more than 2 in every $10 \mathrm{~min}$ with evidence of changes in the cervix over 4-6h. These women had either planned to have an elective CS or their baby was found to be a breech presentation when they presented in early labour or in the latent phase. It is difficult to predict the eventual outcome of the cohort of women recruited into this study as they were delivered by CS while still in the latent phase of labour. However, to validate this approach, we assessed a similar cohort of 44 women who planned to have a vaginal birth after a CS and examined their eventual outcome after they were admitted in spontaneous early labour. Of the 38 women, 31 (82\%) had a vaginal delivery and $7(18 \%)$ an emergency CS for failure to progress in
A TNL

NL

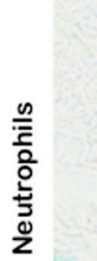

B

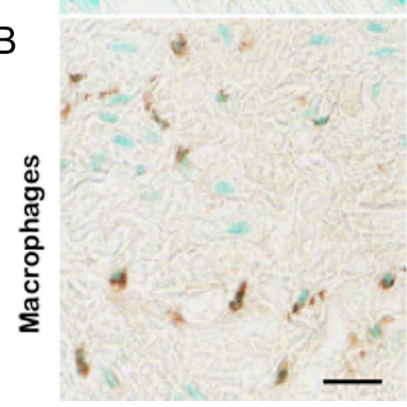

TeL

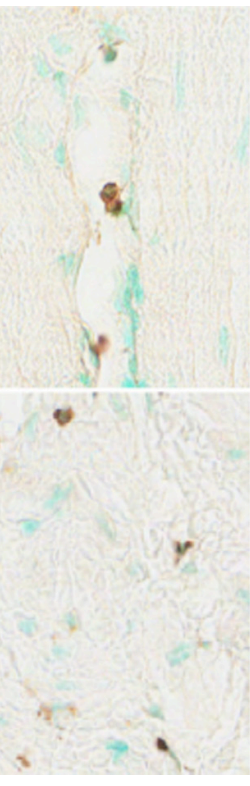

TestL

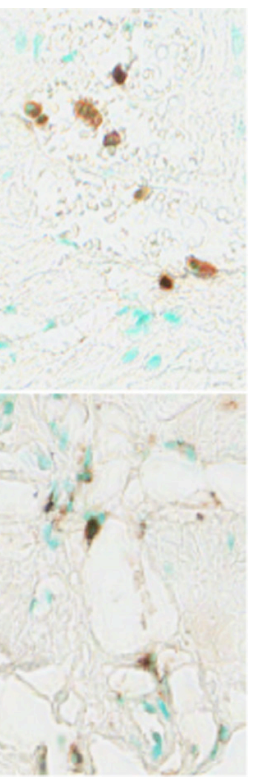

Figure 7

(A and B) Photomicrographs of sections from a biopsy of uterine myometrium from a patient in each study group at TNL, early labour (TeL), or established labour (TesL). Sections were processed by immunohistochemistry to stain neutrophil elastase and cell nuclei counterstained with methyl green as detailed in 'Methods' section. Scale bar $=25 \mu \mathrm{m}$. (A) The data were normally distributed and analysed using an ANOVA followed by a Dunnett's post-hoc test for three groups or more. (B) Photomicrographs from myometrium in biopsy of uterus from women at term no labour (TNL; $39.3 \pm 0.8$ weeks, $n=8$ ), TeL $(39.6 \pm 1.1$ weeks, $n=7)$, and term established labour (TestL, $38.5 \pm 1.3, n=8$ ). Sections were stained by immunohistochemistry for macrophages (CD68) and cell nuclei counterstained with methylgreen. Density of cell nuclei (CN) and macrophages were counted by Stereologer (St, $n=5)$ or Manual (M, $n=7-8)$ as detailed in 'Methods' section. Scale bar $=50 \mu \mathrm{m}$. The data were normally distributed and analysed using an ANOVA followed by a Dunnett's post-hoc test for three groups or more. 
labour. 30 of these women spontaneously laboured and delivered within 36 hours of presenting to the maternity unit. One woman delivered between 36 and $48 \mathrm{~h}$.

Myometrial transcription factor activation has not been studied extensively during human pregnancy. Although many studies have used primary myometrial cell cultures to investigate the signalling pathways activated by stretch, NFkB, AP-1 and C/EBP (Sooranna et al. 2004, 2005, 2007, Terzidou et al. 2005), and inflammation, NFkB and AP-1 (Allport et al. 2001, Pieber et al. 2001, Sooranna et al. 2007, Khanjani et al. 2011b). Condon and coworkers reported that $\mathrm{NFkB}$ was activated in fundal myometrial samples obtained from women in active labour, between 2 and $9 \mathrm{~cm}$ or after vaginal delivery (Condon et al. 2006), we were not able to replicate these findings in a previous study (Khanjani et al. 2011a). In the mouse, NFkB activity peaks prior to labour on day 18, while AP-1 activity peaks on day before progressively declining to day 18 and increasing again in labour, while C/EBP activation is consistently low (MacIntyre et al. 2014). Intriguingly, in the current study, p65 was more active in the PTNL samples than that in the TNL samples. However, cytokine levels were not elevated in the PTNL samples suggesting that it was acting in a pro-inflammatory manner. Indeed, changes in the activity of other transcription factors and molecular switches can modulate the effect of transcription factor activation. However, with the onset of labour, the increase in p65 activity is associated with increased cytokine mRNA expression and could be having other effects, for example, on PR transcriptional activity, facilitating the functional withdrawal of progesterone as has been suggested previously (Pieber et al. 2001, Hardy et al. 2006) or the increased expression of prolabour genes such as oxytocin receptor or COX-2 (Lindstrom \& Bennett 2005, Khanjani et al. 2011a,b).

Most gene array studies have reported increased expression of inflammatory genes with established labour (Bisits et al. 2005, Esplin et al. 2005, Breuiller-Fouche \& Germain 2006, Bollapragada et al. 2009, Mittal et al. 2010, Weiner et al. 2010). Maul and coworkers also examined the mRNA expression of a range of cytokines, in lower segment myometrial samples obtained at the time of emergency performed for pathologic fetal heart rate pattern and dystocia (including cephalopelvic disproportion) and found that the mRNA expression of IL-1 $\beta$, IL-6, CXCL8, but not TNF $\alpha$ (similar to our data), was increased from $6 \mathrm{~cm}$ dilatation, but not before (Maul et al. 2002). In a second study, this group found that protein levels of myometrial IL- 6 and CXCL8 were increased from 4 to $6 \mathrm{~cm}$ dilatation and that mRNA expression of both was localized to the glandular epithelium of the cervix (Kemp et al. 2002). More recently, Srikhajon and coworkers reported that a range of cytokines were increased in lower segment myometrial samples obtained at the time of CS performed in established labour $(>3 \mathrm{~cm}$, however, the clinical indication for the CS was not reported) (Srikhajon et al. 2014). Interestingly, Young and coworkers found that IL-1 $\beta$, IL-6, CXCL8 and TNF $\alpha$ immunoreactivity was restricted to leukocytes in the myometrium (Young et al. 2002). However, we found relatively few leukocytes either in early or established labour and while we did not assess their activation status, it seems unlikely that these leukocytes are the exclusive source of the increased myometrial cytokine levels. Indeed, we found that primary cultures of myometrial cells were able to produce significant amounts of cytokines in response to stretch and to IL-1 $\beta$ (Hua et al. 2012), suggesting that these cells could account for the increased cytokine levels.

Earlier work by Norman and coworkers, using myometrial samples from women in established labour $(>3 \mathrm{~cm}$ and $<9 \mathrm{~cm}$ ), showed that there is an increase in the inflammatory cell infiltration with labour (Thomson et al. 1999). Similarly, the work of Keski-Nisula, who examined myometrial sections from 646 consecutive women who underwent CS at various stages of pregnancy, found that myometrial inflammation was rare before the onset of labour and more common with advanced cervical dilatation and in the presence of chorioamnionitis (KeskiNisula et al. 2003). We too found an increase in neutrophil numbers in early labour, but these were marginating or perivascular and not in the substance of the myometrium. This increase may reflect the increase in myometrial adhesion molecule production reported by Osman and coworkers (Osman et al. 2006). Further, our study was distinct from these earlier studies, in that we excluded samples from women who had a slow labour, limiting the study to those women who had a normally progressing labour. Most previous studies did not define whether the CS was performed for failure to progress or for fetal distress, but given that the majority of CS are performed for failure to progress, then these are likely to make up the majority of the cases. This indication would typically be associated with a longer labour and greater myometrial work and therefore probably associated with a greater inflammatory response. One study has investigated gene expression in women having a CS for dystocia compared to normally progressive labour (Brennan et al. 2011). They found that 70 genes were differentially expressed, all 
12 related to inflammation were reduced in the dystocia group; however, there were only 4 subjects in each group and both groups had been treated with oxytocin to accelerate labour progression (Brennan et al. 2011). The CS in the control group was performed at full dilatation for malposition, while the CS for dystocia was performed at between 2 and $4 \mathrm{~cm}$ and no comment was made as to whether there were signs of obstructed labour in the dystocia group or whether there were regular uterine contractions in response to the oxytocin (Brennan et al. 2011). Consequently, the exact pattern of gene expression in obstructed labour is yet to be defined.

The crucial question is whether our findings are also applicable to preterm labour, in our studies in myometrium taken from the women in early preterm labour, we found that samples from women with chorioamnionitis, idiopathic and twin preterm labour showed significant myometrial inflammation, those from women with an abruption did not (N Singh, B Herbert, GR Sooranna, L Edey, SR Sooranna \& MR Johnson, unpublished observations).

We found that while the mRNA of IL-6, CXCL8 and CXCL1 (and to a lesser extent $I L-1 \beta$ ) increased in established labour in association with an increase in their respective proteins, there was no increase in the mRNA expression of $I L-4, I L-10, C C L 2$ and $C X C L 2$, but their protein levels were increased. This suggests the existence of a posttranscriptional regulation of cytokine levels as has been described previously (Anderson 2008). We have observed a very similar phenomenon, in ru486-treated mice, where, interestingly, there are increases in protein levels of IL-4, IL-10, CCL2 and CXCL1 and several cytokines, independent of any change in mRNA expression (Edey et al. unpublished observation). One possible explanation for these observations involves a p38-mediated improved efficiency of mRNA translation that has been described in the myocardium (Streicher et al. 2010); we are currently investigating this possibility.

We made the decision to use singleton analysis in the multiplex assays to allow us to compare the maximum number of samples from different groups in the same assay, reasoning that the inclusion of greater numbers of samples would allow us to draw more reliable conclusions about the presence or absence of inflammation across the different stages of pregnancy and labour. The original description of the multiplex assays gives an intra-assay coefficient of variation $2.2-3.4 \%$. We did not repeat this work (duPont et al. 2005). Similarly, when the luminex multiplex was originally introduced, a comparative paper showed that the luminex multiplex performed best compared to other multiplex platforms when compared with single analyte ELISAs (Fu et al. 2010). In addition, the multiplex data are fairly consistent across multiple analytes (40), showing no difference between TNL and term early labour (TeL) samples, supporting our conclusions that inflammation occurs after rather than before the onset of labour.

Bayesian networks of cytokine interactions were remarkably consistent across all four settings, suggesting that these inflammatory network structures were broadly conserved across scenarios. This lends credence to the timing of network activation being the preponderant difference between these groups rather than being directly attributable to intrinsic alterations in cytokine interrelationships or profile perturbations. Moreover, any minor differences noted appeared to occur between labouring and non-labouring networks. Among these, CTACK (CCL27) displayed a stepwise relative increase in profile between early and established labour, while I-TAC (CXCL11) was noted to be at relatively elevated concentrations in the early labouring group. Notwithstanding, these changes did not result in downstream network effects, in line with this hypothesis. The nature of these changes is unclear but may relate to altered lymphocyte trafficking in association with the onset of labour. Intriguingly, SDF-1 $\alpha$ (CXCL12) was invariably present as a major terminal node in all networks. Although this may be a reflection of the fact that Bayesian networks preclude the existence of structural feedback loops, SDF-1 $\alpha$ 's (CXCL12) position is nevertheless determined by the confidence of its directed edges. The physiological basis for this position is unclear given the relative paucity of information relating to its role in the onset of labour, although it is likely that it plays a role in the immunomodulation of the later stages of pregnancy and the onset of labour (Rzepka et al. 2016).

A potential confounder in our analysis is that due to the limitation in the amount of tissue available as we were not able to use the complete cohort of women throughout as we ran out of 4 PTNL, 5 TNL and 4 TeL accounting for the variation in $\mathrm{n}$ number and demographic data.

These data show that myometrial inflammation is unlikely to have a role in the onset of term labour. Our finding of NFkB activation in early labour may indicate that labour is a stretch-induced process or may simply be secondary to increased myometrial activity. It seems likely that NFkB activation in early labour is responsible for the later increase in cytokine mRNA and protein levels. 


\section{Supplementary data}

This is linked to the online version of the paper at http://dx.doi.org/10.1530/ JOE-17-0318.

\section{Declaration of interest}

The authors declare that there is no conflict of interest that could be perceived as prejudicing the impartiality of this review.

\section{Funding}

This work was supported by Borne, the Imperial NIHR Biomedical Research Centre. S Y efforts were in part supported by NIH HD954931 and Cerebra. Some of the data from this paper was presented as a poster at the 62nd Annual Scientific meeting, Society for Reproductive Investigation, San Francisco, March 25th-28th 2015.

\section{Acknowledgements}

The technical assistance of Anne Heuerman and Patricia Mazurek for tissue processing and analyses of data from biopsy sections was appreciated.

\section{References}

Adams Waldorf KM, Singh N, Mohan AR, Young RC, Ngo L, Das A, Tsai J, Bansal A, Paolella L, Herbert BR, et al. 2015 Uterine overdistention induces preterm labor mediated by inflammation: observations in pregnant women and nonhuman primates. American Journal of Obstetrics and Gynecology 213 830.e1-830.e19. (doi:10.1016/j. ajog.2015.08.028)

Allport VC, Pieber D, Slater DM, Newton R, White JO \& Bennett PR 2001 Human labour is associated with nuclear factor-kappaB activity which mediates cyclo-oxygenase- 2 expression and is involved with the 'functional progesterone withdrawal'. Molecular Human Reproduction 7 581-586. (doi:10.1093/molehr/7.6.581)

Anderson P 2008 Post-transcriptional control of cytokine production. Nature Immunology 9 353-359. (doi:10.1038/ni1584)

Azziz R, Cumming J \& Naeye R 1988 Acute myometritis and chorioamnionitis during cesarean section of asymptomatic women. American Journal of Obstetrics and Gynecology 159 1137-1139. (doi:10.1016/0002-9378(88)90431-0)

Bisits AM, Smith R, Mesiano S, Yeo G, Kwek K, MacIntyre D \& Chan EC 2005 Inflammatory aetiology of human myometrial activation tested using directed graphs. PLoS Computational Biology 1 132-136. (doi:10.1371/journal.pcbi.0010019)

Bollapragada S, Youssef R, Jordan F, Greer I, Norman J \& Nelson S 2009 Term labor is associated with a core inflammatory response in human fetal membranes, myometrium, and cervix. American Journal of Obstetrics and Gynecology 200 104.e101-104.e111. (doi:10.1016/j. ajog.2008.08.032)

Brennan DJ, McGee SF, Rexhepaj E, O'Connor DP, Robson M \& O’Herlihy C 2011 Identification of a myometrial molecular profile for dystocic labor. BMC Pregnancy Childbirth 11 74. (doi:10.1186/1471-2393-11-74)

Breuiller-Fouche M \& Germain G 2006 Gene and protein expression in the myometrium in pregnancy and labor. Reproduction 131 837-850. (doi:10.1530/rep.1.00725)

Burke M, Zangenehpour S, Mouton PR \& Ptito M 2009 Knowing what counts: unbiased stereology in the non-human primate brain. Journal of Visualized Experiments $\mathbf{2 7}$ e1262.

Condon JC, Jeyasuria P, Faust JM \& Mendelson CR 2004 Surfactant protein secreted by the maturing mouse fetal lung acts as a hormone

http://joe.endocrinology-journals.org

DOI: $10.1530 / \mathrm{JOE}-17-0318$
() 2017 Society for Endocrinology Printed in Great Britain that signals the initiation of parturition. PNAS $1014978-4983$. (doi:10.1073/pnas.0401124101)

Condon JC, Hardy DB, Kovaric K \& Mendelson CR 2006 Up-regulation of the progesterone receptor (PR)-C isoform in laboring myometrium by activation of nuclear factor-kappaB may contribute to the onset of labor through inhibition of PR function. Molecular Endocrinology 20 764-775. (doi:10.1210/me.2005-0242)

Dubicke A, Ekman-Ordeberg G, Mazurek P, Miller L \& Yellon SM 2016 Density of stromal cells and macrophages associated with collagen remodeling in the human cervix in preterm and term birth. Reproductive Sciences 23 595-603. (doi:10.1177/1933719115616497)

duPont NC, Wang K, Wadhwa PD, Culhane JF \& Nelson EL 2005 Validation and comparison of luminex multiplex cytokine analysis kits with ELISA: determinations of a panel of nine cytokines in clinical sample culture supernatants. Journal of Reproductive Immunology 66 175-191. (doi:10.1016/j.jri.2005.03.005)

Esplin MS, Fausett MB, Peltier MR, Hamblin S, Silver RM, Branch DW, Adashi EY \& Whiting D 2005 The use of cDNA microarray to identify differentially expressed labor-associated genes within the human myometrium during labor. American Journal of Obstetrics and Gynecology 193 404-413. (doi:10.1016/j. ajog.2004.12.021)

Field SL, Dasgupta T, Cummings M, Savage RS, Adebayo J, McSara H, Gunawardena J \& Orsi NM 2015 Bayesian modeling suggests that IL-12 (p40), IL-13 and MCP-1 drive murine cytokine networks in vivo. BMC Systems Biology 9 76. (doi:10.1186/s12918-015-0226-3)

Fu Q, Zhu J \& Van Eyk JE 2010 Comparison of multiplex immunoassay platforms. Clinical Chemistry 56 314-318. (doi:10.1373/ clinchem.2009.135087)

Gundersen HJ \& Jensen EB 1987 The efficiency of systematic sampling in stereology and its prediction. Journal of Microscopy 147 229-263. (doi:10.1111/j.1365-2818.1987.tb02837.x)

Haram K, Mortensen JH \& Morrison JC 2015 Tocolysis for acute preterm labor: does anything work. Journal of Maternal-Fetal and Neonatal Medicine 28 371-378. (doi:10.3109/14767058.2014.918095)

Hardy DB, Janowski BA, Corey DR \& Mendelson CR 2006 Progesterone receptor plays a major antiinflammatory role in human myometrial cells by antagonism of nuclear factor-kappaB activation of cyclooxygenase 2 expression. Molecular Endocrinology 20 2724-2733. (doi:10.1210/me.2006-0112)

Hua R, Pease JE, Sooranna SR, Viney JM, Nelson SM, Myatt L, Bennett PR \& Johnson MR 2012 Stretch and inflammatory cytokines drive myometrial chemokine expression via NF-kappaB activation. Endocrinology 153 481-491. (doi:10.1210/en.2011-1506)

Hutchinson JL, Rajagopal SP, Yuan M \& Norman JE 2014 Lipopolysaccharide promotes contraction of uterine myocytes via activation of Rho/ROCK signaling pathways. FASEB Journal $\mathbf{2 8}$ 94-105. (doi:10.1096/fj.13-237040)

Kemp B, Menon R, Fortunato SJ, Winkler M, Maul H \& Rath W 2002 Quantitation and localization of inflammatory cytokines interleukin-6 and interleukin-8 in the lower uterine segment during cervical dilatation. Journal of Assisted Reproduction and Genetics 19 215-219. (doi:10.1023/A:1015354701668)

Keski-Nisula LT, Aalto ML, Kirkinen PP, Kosma VM \& Heinonen ST 2003 Myometrial inflammation in human delivery and its association with labor and infection. American Journal of Clinical Pathology 120 217-224. (doi:10.1309/KC6KDTX98LFYB3J7)

Khanjani S, Kandola MK, Lindstrom TM, Sooranna SR, Melchionda M, Lee YS, Terzidou V, Johnson MR \& Bennett PR 2011a NF-kappaB regulates a cassette of immune/inflammatory genes in human pregnant myometrium at term. Journal of Cellular and Molecular Medicine 15 809-824. (doi:10.1111/j.1582-4934.2010.01069.x)

Khanjani S, Terzidou V, Lee YS, Thornton S, Johnson MR \& Bennett PR $2011 b$ Synergistic regulation of human oxytocin receptor promoter by CCAAT/enhancer-binding protein and RELA. Biology of Reproduction 85 1083-1088. (doi:10.1095/biolreprod.111.092304) 
Lindstrom TM \& Bennett PR 2005 The role of nuclear factor kappa B in human labour. Reproduction 130 569-581. (doi:10.1530/rep.1.00197)

MacIntyre DA, Lee YS, Migale R, Herbert BR, Waddington SN, Peebles D, Hagberg H, Johnson MR \& Bennett PR 2014 Activator protein 1 is a key terminal mediator of inflammation-induced preterm labor in mice. FASEB Journal 28 2358-2368. (doi:10.1096/fj.13-247783)

Madsen G, Zakar T, Ku CY, Sanborn BM, Smith R \& Mesiano S 2004 Prostaglandins differentially modulate progesterone receptor-A and -B expression in human myometrial cells: evidence for prostaglandin-induced functional progesterone withdrawal. Journal of Clinical Endocrinology and Metabolism 89 1010-1013. (doi:10.1210/ jc.2003-031037)

Maul H, Nagel S, Welsch G, Schafer A, Winkler M \& Rath W 2002 Messenger ribonucleic acid levels of interleukin- 1 beta, interleukin- 6 and interleukin- 8 in the lower uterine segment increased significantly at final cervical dilatation during term parturition, while those of tumor necrosis factor alpha remained unchanged. European Journal of Obstetrics, Gynecology, and Reproductive Biology 102 143-147. (doi:10.1016/S0301-2115(01)00606-6)

Mesiano S, Chan EC, Fitter JT, Kwek K, Yeo G \& Smith R 2002 Progesterone withdrawal and estrogen activation in human parturition are coordinated by progesterone receptor A expression in the myometrium. Journal of Clinical Endocrinology and Metabolism $\mathbf{8 7}$ 2924-2930. (doi:10.1210/jcem.87.6.8609)

Mittal P, Romero R, Tarca AL, Gonzalez J, Draghici S, Xu Y, Dong Z, NhanChang CL, Chaiworapongsa T, Lye S, et al. 2010 Characterization of the myometrial transcriptome and biological pathways of spontaneous human labor at term. Journal of Perinatal Medicine 38 617-643. (doi:10.1515/JPM.2010.097)

Montalbano AP, Hawgood S \& Mendelson CR 2013 Mice deficient in surfactant protein A (SP-A) and SP-D or in TLR2 manifest delayed parturition and decreased expression of inflammatory and contractile genes. Endocrinology 154 483-498. (doi:10.1210/en.2012-1797)

NICE 2014 Intrapartum care for healthy women and babies. NICE Clinical Guideline 190 [CG190]. London, UK: NICE. (available at: https://www.nice.org.uk/guidance/cg190)

Osman I, Young A, Ledingham MA, Thomson AJ, Jordan F, Greer IA \& Norman JE 2003 Leukocyte density and pro-inflammatory cytokine expression in human fetal membranes, decidua, cervix and myometrium before and during labour at term. Molecular Human Reproduction 9 41-45. (doi:10.1093/molehr/gag001)

Osman I, Young A, Jordan F, Greer IA \& Norman JE 2006 Leukocyte density and proinflammatory mediator expression in regional human fetal membranes and decidua before and during labor at term. Journal of the Society for Gynecologic Investigation 13 97-103. (doi:10.1016/j. jsgi.2005.12.002)

Pieber D, Allport VC, Hills F, Johnson M \& Bennett PR 2001 Interactions between progesterone receptor isoforms in myometrial cells in human labour. Molecular Human Reproduction 7 875-879. (doi:10.1093/ molehr/7.9.875)

Rajagopal SP, Hutchinson JL, Dorward DA, Rossi AG \& Norman JE 2015 Crosstalk between monocytes and myometrial smooth muscle in culture generates synergistic pro-inflammatory cytokine production and enhances myocyte contraction, with effects opposed by progesterone. Molecular Human Reproduction 21 672-686. (doi:10.1093/molehr/gav027)

Rzepka R, Dolegowska B, Rajewska A, Salata D, Budkowska M, Kwiatkowski S \& Torbe A 2016 Diagnostic potential of evaluation of SDF-1alpha and sRAGE levels in threatened premature labor. BioMed Research International 2016 2719460. (doi:10.1155/2016/2719460)
Smith R 2007 Parturition. New England Journal of Medicine 356 271-283. (doi:10.1056/NEJMra061360)

Sooranna SR, Lee Y, Kim LU, Mohan AR, Bennett PR \& Johnson MR 2004 Mechanical stretch activates type 2 cyclooxygenase via activator protein-1 transcription factor in human myometrial cells. Molecular Human Reproduction 10 109-113. (doi:10.1093/molehr/ gah021)

Sooranna SR, Engineer N, Loudon JA, Terzidou V, Bennett PR \& Johnson MR 2005 The mitogen-activated protein kinase dependent expression of prostaglandin $\mathrm{H}$ synthase- 2 and interleukin- 8 messenger ribonucleic acid by myometrial cells: the differential effect of stretch and interleukin-1\{beta\}. Journal of Clinical Endocrinology and Metabolism 90 3517-3527. (doi:10.1210/jc.2004-1390)

Sooranna SR, Engineer N, Liang Z, Bennett PR \& Johnson MR 2007 Stretch and interleukin 1 beta: pro-labour factors with similar mitogen-activated protein kinase effects but differential patterns of transcription factor activation and gene expression. Journal of Cellular Physiology 212 195-206. (doi:10.1002/jcp.21019)

Srikhajon K, Shynlova O, Preechapornprasert A, Chanrachakul B \& Lye S 2014 A new role for monocytes in modulating myometrial inflammation during human labor. Biology of Reproduction 9110. (doi:10.1095/biolreprod.113.114975)

Stock S \& Norman J 2010 Preterm and term labour in multiple pregnancies. Seminars in Fetal and Neonatal Medicine 15 336-341. (doi:10.1016/j.siny.2010.06.006)

Streicher JM, Ren S, Herschman H \& Wang Y 2010 MAPK-activated protein kinase-2 in cardiac hypertrophy and cyclooxygenase-2 regulation in heart. Circulation Research 106 1434-1443. (doi:10.1161/ CIRCRESAHA.109.213199)

Terzidou V, Sooranna SR, Kim LU, Thornton S, Bennett PR \& Johnson MR 2005 Mechanical stretch up-regulates the human oxytocin receptor in primary human uterine myocytes. Journal of Clinical Endocrinology and Metabolism 90 237-246. (doi:10.1210/jc.2004-0277)

Terzidou V, Lee Y, Lindstrom T, Johnson M, Thornton S \& Bennett PR 2006 Regulation of the human oxytocin receptor by nuclear factorkappaB and CCAAT/enhancer-binding protein-beta. Journal of Clinical Endocrinology and Metabolism 91 2317-2326. (doi:10.1210/jc.20052649)

Thomson AJ, Telfer JF, Young A, Campbell S, Stewart CJ, Cameron IT, Greer IA \& Norman JE 1999 Leukocytes infiltrate the myometrium during human parturition: further evidence that labour is an inflammatory process. Human Reproduction 14 229-236. (doi:10.1093/ humrep/15.1.229)

Vandesompele J, De Preter K, Pattyn F, Poppe B, Van Roy N, De Paepe A \& Speleman F 2002 Accurate normalization of real-time quantitative RT-PCR data by geometric averaging of multiple internal control genes. Genome Biology 3 RESEARCH0034.

Weiner CP, Mason CW, Dong Y, Buhimschi IA, Swaan PW \& Buhimschi CS 2010 Human effector/initiator gene sets that regulate myometrial contractility during term and preterm labor. American Journal of Obstetrics and Gynecology 202 474.e471-474.e420. (doi:10.1016/j. ajog.2010.02.034)

Wing DA \& Sheibani L 2015 Pharmacotherapy options for labor induction. Expert Opinion on Pharmacotherapy 16 1657-1668. (doi:10.1517/14656566.2015.1060960)

Young A, Thomson AJ, Ledingham M, Jordan F, Greer IA \& Norman JE 2002 Immunolocalization of proinflammatory cytokines in myometrium, cervix, and fetal membranes during human parturition at term. Biology of Reproduction 66 445-449. (doi:10.1095/ biolreprod66.2.445)

Received in final form 24 July 2017

Accepted 1 August 2017

Accepted Preprint published online 1 August 2017 http://joe.endocrinology-journals.org

DOI: $10.1530 / J O E-17-0318$
(C) 2017 Society for Endocrinology Printed in Great Britain
Published by Bioscientifica Ltd 